\title{
IMPLEMENTASI MEDIA PEMBELAJARAN BERBASIS M-LEARNING MENGGUNAKAN MODEL BLENDED POE2WE UNTUK MENINGKATKAN MOTIVASI BELAJAR PESERTA DIDIK
}

\author{
Irfan Maulana ${ }^{1}$, Nana $^{2}$ \\ Jurusan Pendidikan Fisika, \\ Fakultas Keguruan dan Ilmu Pendidikan,Universitas Siliwangi \\ Tasikmalaya Jawa Barat Indonesia 46115 \\ Email : 1001irfanmaulana@gmail.com
}

\begin{abstract}
The purpose of this study is to describe the application of learning media based on m-learningg using the POE2WE blender model to increase student learning motivation. This writing is motivated by increased learning in students who need good learning media and still use learning materials that have not been maximized. The method used in this renewal is the study of literature by studying some literature to be analyzed and made conclusions. The results of discussions about the application of m-learning based learning media using the POE2WE blender model can be a solution to the problems encountered in the teaching and learning process sponsored by students. The mixed POE2WE model is applied to students in High School with several steps including; participants do learning using smartphones, at faceto-face meetings students learn to use learning with teachers, in independent learning students do distance learning so as to increase their own willingness to do learning. The results of this study prove that learning media based on m-learning is feasible by using the POE2WE model to increase students' learning motivation and be able to take advantage of current technological advances.
\end{abstract}

Keywords: Blended POE2WE, M-learning, Learning Motivation

ABSTRAK: Tujuan penulisan ini untuk mendeskripsikan penerapan media pembelajaran berbasis m-learng menggunakan model blended POE2WE untuk meningkatkan motivasi belajar peserta didik. Penulisan ini dilatar belakang oleh kurangnya motivasi belajar pada peserta didik karenanya kurangnya media pembelajaran yang bagus dan masih kurangnya penguasaan materi sehingga pembelajaran yang diterapkan belum maksimal. Metode yang digunakan dalam penulisan ini yaitu dengan studi kepustakaan dengan mengkaji beberapa literatur untuk dianalisis dan dibuat kesimpulan. Hasil penulisan menunjukkan bahwa penerapan media pembelajaran berbasis m-learning menggunakan model blended POE2WE dapat menjadi solusi dari permasalahan yang ditemui dalam proses belajar mengajar terutama motivasi belajar peserta didik. Model blended POE2WE diterapkan kepada peserta didik di Sekolah Menengah Atas dengan beberapa langkah antara lain; peserta melalukan pembelajaran dengan menggunakan smartphone, pada pertemuan face to face peserta didik melakukan pembelajaran menggunakan mobile learning dengan bimbingan seorang guru, dalam pembelajaran mandiri peserta didik melakukan pembelajaran jarak jauh sehingga adanya kemauan sendiri dalam melakukan pembelajaran. Hasil penelitian ini menunjukkan bahwa media pembelajaran berbasis m-learning layak dengan menggunakan model blended POE2WE dapat meningkatkan motivasi belajar peserta didik dan dapat memanfaatkan kemajuan teknologi masa kini. 
Kata Kunci: Blended POE2WE, M-learning, Motivasi Belajar

\section{PENDAHULUAN}

Perkembangan teknologi dari waktu ke waktu berjalan dengan pesat, contohnya pada handphone yang sekarang telah berevolusi menjadi smartphone. Smartphone adalah telepon genggam atau telepon seluler pintar yang dilengkapi dengan fitur yang mutakhir dan berkemampuan tinggi layaknya sebuah computer. Harga smartphone saat ini relatif semakin murah merupakan faktor pendukung dan penggunaannya juga meningkat. Didalam smartphone terdiri dari beberapa software atau perangkat mobile untuk mencari informasi dan sebagainya. Semakin banyaknya siswa yang memiliki dan menggunakan perangkat mobile, maka semakin besar pula peluang penggunaan perangkat teknologi dalam dunia pendidikan.

Media pembelajaran yang memanfaatkan teknologi telepon seluler disebut dengan mobile learning. menurut Fatimah dalam Astutia, dkk (2017: 57) Mobile learning merupakan salah satu alternatif pengembangan media pembelajaran. Kehadiran mobile learning ditujukan sebagai pelengkap pembelajaran serta memberikan kesempatan pada peserta didik untuk mempelajari materi yang kurang dikuasai di manapun dan kapanpun. Menurut Riyanto, dkk (2006)dalam Fatimah dan Mukti (2014: 59-64) Penggunaan mobile learning (M-Learning) merupakan pembelajaran yang unik karena siswa dapat mengakses materi pembelajaran setiap waktu sehingga hal ini dapat meningkatkan perhatian siswa dalam memahami materi pelajaran, membuat pembelajaran menjadi pervasif, dan dapat memotivasi siswa.

Pada era digital atau era informasi pada saat ini diperlukannya inovasi baru dalam memanfaatkan media pembelajaran fisika, media yang paling mudah di digunakan dan didapatkan adalah mobile learning. Teknologi yang berperan dalam proses pembelajaran mampu mempengaruhi pengembangan kurikulum dengan tiga cara, yaitu: (1) penggunaan teknologi baru menjadi tujuan sosial dari kurikulum, (2) teknologi menyediakan sumber daya bagi perkembangan kurikulum, karena dapat membuat pendidik menemukan dan mengumpulkan materi ajar dan juga menuntun peserta didik dalam pembelajaran. (3) teknologi dapat menyediakan alat untuk menilai berbagai bidang praktik, seperti simulasi, yaitu membuat model atau alat visualisasi pada bidang sains dan alat menganalisis naskah pada literatur Darling, Hammond, dan Bransford (2005) dalam lubis dan ikhsan (2015: 191201).

Berdasarkan penjelasan yang telah dipaparkan, sangat memungkinkan bahwa pembelajaran fisika dengan menggunakan Smartphone pada setiap materi memberikan pengalaman belajar kepada siswa yang lebih bermakna.

\section{METODE PENELITIAN}

Penelitian ini menggunakan metode studi kepustakaan. Data dikumpulkan untuk dianalisis kemudian disajikan dalam hasil dan pembahasan agar dapat dibuat kesimpulan. Teknik analisis data yang digunakan adalah analisis isi. Untuk menjaga ketepatan pengkajian dan mencegah kesalahan informasi dalam analisis data maka dilakukan pengecekan antar pustaka dan membaca ulang pustaka.

\section{HASIL DAN PEMBAHASAN \\ 3.1 blended POE2WE}


Model POE2WE merupakan model pembelajaran yang dikembangkan untuk mengetahui pemahaman peserta didik mengenai suatu konsep dengan pendekatan konstruktivistik. Model ini membangun pengetahuan dengan urutan proses yaitu meramalkan atau memprediksi solusi dari permasalahan, melakukan eksperimen untuk membuktikan prediksi, kemudian menjelaskan hasil eksperimen yang diperoleh secara lisan maupun tertulis, membuat contoh penerapan dalam kehidupan seharihari, menuliskan hasil diskusi dan memuat evaluasi tentang pemahaman peserta didik baik secara lisan maupun tertulis Nana, dkk (2014: 56-65). Penggabungan tahapan-tahapan pembelajaran model POEW dan model pembelajaran Fisika dengan Pendekatan Konstruktivistik maka dapat di susun langkah-langkah pembelajaran model POE2WE secara terinci sebagai berikut:

- Prediction. Tahap prediction yaitu peserta didik membuat prediksi atau dugaan awal terhadap suatu permasalahan. Permasalahan yang ditemukan berasal dari pertanyaan dan gambar tentang materi yang disampaikan oleh guru yang ada di Lembar Kerja peserta didik (LKS)/buku peserta didik sebelum peserta didik membuat prediksi. Pembuatan prediksi jawaban tahap Prediction pada model POEW identik dengan fase Engagenent pada pendekatan konstruktivistik. Guru mengajukan pertanyaan yang dapat mendorong peserta didik untuk dapat membuat prediksi atau jawaban sementara dari suatu permasalahan.

- Observation. Tahap Observation yaitu untuk membuktikan prediksi yang telah di buat oleh pesera didik. Peserta didik diajak melakukan eksperimen berkaitan dengan masalah atau persoalan yang di temukan. Selanjutnya peserta didik mengamati apa yang terjadi, kemudian peserta didik menguji kebenaran dari dugaan sementara yang telah dibuat. Tahap Observation pada model POEW identik dengan fase Exploration pada pendekatan konstruktivistik.

- Explanation. Tahap Explanation atau menjelaskan yaitu peserta didik memberikan penjelasan terhadap hasil eksperimen yang telah dilakukan. Penjelasan dari peserta didik dilakukan melalui diskusi dengan anggota kelompok kemudian tiap kelompok mempresentasikan hasil diskusinya di depan kelas. Jika prediksi yang di buat peserta didik ternyata terjadi di dalam eksperimen, maka guru membimbing peserta didik merangkum dan memberi penjelasan untuk menguatkan hasil eksperimen yang dilakukan. Namun jika prediksi peserta didik tidak terjadi dalam eksperimen, maka guru membantu peserta didik mencari penjelasan mengapa prediksi atau dugaannya tidak benar. Tahap explanation identik dengan fase explanation pada pendekatan konstuktivistik.

- Elaboration. Tahap elaboration yaitu peserta didik membuat contoh atau menerapkan konsep dalam kehidupan sehari-hari. Tahap elaboration di ambil dari pendekatan konstruktivistik. Tahap ini guru medorong peserta didik untuk menerapkan konsep baru dalam situasi baru sehingga peserta didik lebih memahami konsep yang di ajarkan guru. Tahap ini pengembangan dari pendekatan konstruktivistik.

- Write. Tahap write atau menulis yaitu melakukan komunikasi secara tertulis,merefleksikan pengetahuan dan gagasan yang dimiliki peserta didik.

- Evaluation. Tahap Evaluation yaitu evaluasi terhadap pengetahuan, keterampilan dan perubahan proses berfikir peserta didik. Pada tahap ini peserta didik di 
evaluasi tentang materi gerak lurus berupa lisan maupun tulisan. Tahap ini merupakan pengembangan dari pendekatan konstruktivistik

Table 1. Kegiatan pembelajaran Model Pembelajaran Model POE2WE

\begin{tabular}{|c|c|c|c|}
\hline No & Fase-Fase & Kegiatan Guru & Kegiatan Peserta Didik \\
\hline 1. & Prediction & 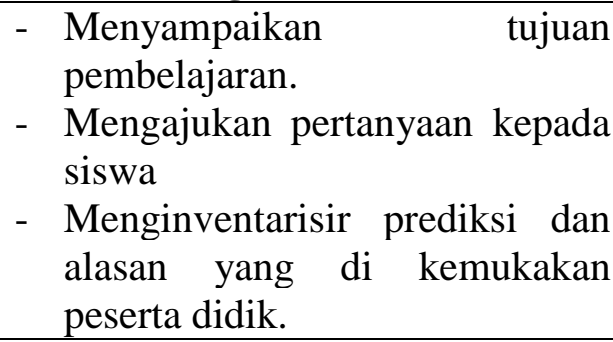 & $\begin{array}{llr}\text { - } & \text { Memperhatikan penjelasandari } \\
& \text { guru. } \\
\text { - } & \text { Memprediksi } & \\
& \text { pertanyaan dari guru } & \\
\text { - } & \text { Mendiskusikan } & \\
& \text { prediksinya } & \text { hasil }\end{array}$ \\
\hline 2. & Observation & $\begin{array}{l}\text { - Mendorong peserta didik untuk } \\
\text { bekerja secara kelompok } \\
\text { - Membagikan LKS } \\
\text { - Mengawasi kegiatan percobaan } \\
\text { yangdilakukan oleh peserta } \\
\text { didik }\end{array}$ & $\begin{array}{lll}\text { - } & \text { Membentuk kelompok } & \\
\text { - } & \text { Melakukan percobaan } \\
\text { - } & \text { Mengumpulkan data hasil } \\
& \text { percobaan } \\
\text { - } & \text { Melakukan diskusi kelompok } \\
\text { - } & \text { Menyimpulkan hasil } \\
& \text { percobaan }\end{array}$ \\
\hline 3. & Explanation & \begin{tabular}{llr} 
- & \multicolumn{3}{l}{ Mendorong peserta didik untuk } \\
menjelaskan hasil percobaan. \\
- & Meminta peserta didik \\
& pempresentasikan & hasil \\
& percobaannya \\
- & Mengklarifikasikan \\
& percobaannya \\
- & Menjelaskan konsep/definisi \\
& baru
\end{tabular} & $\begin{array}{l}\text { - } \text { Mengemukakan pendapatnya } \\
\text { tentang hasil percobaan } \\
\text { - Mengemukakan pendapatnya } \\
\text { tentang gagasan baru } \\
\text { berdasarkan hasil percobaan. } \\
\text { - } \text { Menanggapi presentasi dari } \\
\text { kelompok lain. } \\
\text { - Konsep baru dari guru dapat di } \\
\text { terima }\end{array}$ \\
\hline 4. & Elaboration & 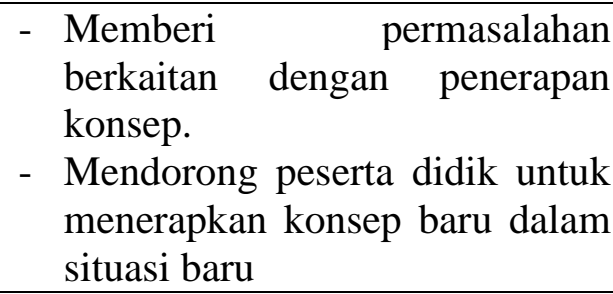 & $\begin{array}{lll}\text { - } & \text { Menerapkan konsep } & \text { baru } \\
\text { dalam situasi baru } & \text { atau } \\
\text { kehidupan sehari-hari. } & \end{array}$ \\
\hline 5. & Write & $\begin{array}{l}\text { - Memberi kesempatan kepada } \\
\text { peserta didik untuk mencatat } \\
\text { hasil diskusi serta kesimpulan. }\end{array}$ & $\begin{array}{l}\text { - Mencatat hasil penjelasan dan } \\
\text { kesimpulan dari guru dan } \\
\text { diskusi kelompok }\end{array}$ \\
\hline 6. & Evaluation & $\begin{array}{l}\text { - } \text { Mengajukan pertanyaan untuk } \\
\text { penilaian proses } \\
\text { - Menilai pengetahuan peserta } \\
\text { didik } \\
\text { - } \begin{array}{l}\text { Memberikan balikan terhadap } \\
\text { jawaban peserta didik }\end{array}\end{array}$ & $\begin{array}{l}\text { - } \text { Menjawab pertanyaan } \\
\text { berdasarkan data } \\
\text { - Mendemonstrasikan } \\
\text { kemampuan dalam penguasaan } \\
\text { konsep }\end{array}$ \\
\hline
\end{tabular}

Istilah "blended learning" dapat diartikan menjadi beberapa makna. Secara umum, blended learning mengacu pada perpaduan lingkungan belajar yang berbeda. Perpaduan ini bisa 
menggabungkan proses pembelajaran asynchronous dan synchronous, face to face dan distance learning. Secara khusus, Thorne (2003) menggambarkan blended learning sebagai "... an opportunity to integrate the innovative and technological advances offered by online learning with the interaction and participation offered in the best of traditional learning..." . Selain itu, Bersin (2004) mendefinisikan blended learning sebagai berikut : "the combination of diferent training "media" (technologies, Activies, types of events) to create an optimum training program for term 'blended" means that traditional instructor-led training is being supplemented with other electronic formats. In the context of this book, blended learning program use many different forms of e-learning, perhaps complemented with instructor-led training and other live formats". Tujuan Blended Learning adalah untuk melakukan sintesis pembelajaran tatap muka dan pembelajaran berbasis online menjadi satu campuran yang terintegrasi sehingga dapat menciptakan dampak yang tinggi, efisien, dan menarik. Secara praktis, blended learning berarti bahwa pembelajaran (pembelajaran tatap muka dalam kelas) juga dilengkapi dengan format elektronik lainnya (e-learning) untuk membuat suatu program pembelajaran yang optimal. Pada awalnya, pemanfaatan E-Learning sangat diunggulkan dibanding dengan Pembelajaran Konvensional secara tatap muka (Face to Face).

Konsep penggabungan yang diusung pada blended Learning membuat pengajaran lebih bermakna. Secara umum, konsep ini dibutuhkan pada saat metode pengajaran jarak jauh tidak begitu dibutuhkan dan pada ada saat mahasiswa membutuhkan penambahan pembelajaran. Berikut ini merupakan saat-saat yang tepat blended learning dibutuhkan:

- Proses belajar mengajar tidak hanya tatap muka, namun menambah waktu pembelajaran dengan memanfaatkan teknologi dunia maya.

- Mempermudah dan mempercepat proses komunikasi non-stop antara pengajar dan peserta didik.

- Peserta didik dan pengajar dapat diposisikan sebagai pihak yang belajar.

- Membantu proses percepatan pengajaran.

Kerangka teori POE2WE ini dibangun berdasarkan pandangan dari beberapa teori yang mengkerangkai model pembelajaran POE2WE. Dalam POE2WE dipadukan tiga jenis interaksi yang meliputi interaksi sosial, inetraksi muatan, dan interaksi dosen. Penjelasan adalah berikut:

- Tipe interaksi pertama adalah dengan dosen yang menjadi fasilitasor active learning dan interaksi tatap muka yang terjadi pada suatu setting sosial. Akan tetapi dosenlah yang merancang dan mengelola urut-urutan pembelajaran dan menyeleksi media yang tepat sebelum berinteraksi dengan mahasiswa. Selanjutnya dosen menggunakan e-learning www.unsil.ac.ad untuk meakukan pembelajaran jarak jauh dan pengumpulan tugas serta komunikasi secara online. Mahasiswa dapat berdiskusi dengan mahasiswa lain dan dengan mahasiswa dapat berdiskusi dengan mahasiswa lainnya dengan dosen pada waktu yang bersamaan sehingga akan terjadi komunikasi interpersonal dan feedback.

- Interaksi kedua adalah dengan muatan interaksi ini menjembatani interaksi kognitif dengan konsep konsep dan keterampilan yang termuat dalam modul pembelajaran. Modul tersebut isertai dengan petunjuk penggunaan dan mind mapping setap topik sehingga tujuan pembelajaran tergambara dengan jelas. c. Terakhir, interaksi sosial dimaksudkan senbagai kemampuan pembelajar (siswa) untuk mempersepsikan diri mereka sebagai sebuah komunitas yang saling 
bergantung secara positif (positive interdependent, cooperation). Interaksi yang demikian itu dapat terjadi di keseluruhan proses pembelajaran karena mereka engerjakan tgas-tugasyang menuntut kerjasama. Sebagaimana diketahui dimensi interaksi (diskursus social)

\subsection{Mobile Learning}

Dikutif dari Sharples (2005) Sebagai bagian dari proses pengembangan teori mobile, anggota inti dariProyek MOBIlearn Eropa mengadakan sesi refleksi selama pertemuan pleno terakhirnya di Singapura Januari 2005, untuk membahas apa yang khas tentang pembelajaran seluler dan "apa yang kita ketahui sekarangbahwa kami tidak melakukannya di awal proyek ". MOBIlearn melibatkan 24 mitra dari Eropa Komunitas, Israel, Swiss, AS dan Australia untuk mengembangkan metode dan sistem baru untuk pembelajaran mobile. Daftar di bawah ini merangkum temuan dari sesi refleksi akhir, mewakili kebijaksanaan kolektif dua belas pemimpin penelitian setelah 30 bulan proyek.

- Pelajarlah yang mobile, bukan teknologinya: Interaksi antara pembelajaran dan teknologi adalah kompleks dan bervariasi, dengan peserta didik secara oportunis mengambil teknologi apa pun yang siap digunakan mereka bergerak di antara pengaturan, termasuk ponsel dan telepon rumah, milik mereka sendiri dan orang lain komputer, serta buku dan buku catatan.

- Belajar terjalin dengan kegiatan lain sebagai bagian dari kehidupan sehari-hari: Belajar tidak mudah dipisahkan dari kegiatan sehari-hari lainnya seperti percakapan, membaca, atau menonton televisi, dan kegiatan ini dapat menjadi sumber dan konteks untuk pembelajaran.

- Belajar dapat menghasilkan serta memuaskan tujuan: Belajar dapat dimulai oleh tujuan eksternal (seperti kurikulum atau rencana studi), atau oleh kebutuhan dan masalah pelajar, atau bisa timbul dari rasa ingin tahu atau kebetulan, mendorong pelajar untuk membentuk tujuan baru yang kemudian dapat dieksplorasi melalui studi formal atau informal.

- Kontrol dan manajemen pembelajaran dapat didistribusikan: Di dalam kelas, control penuh pembelajaran tetap dengan guru, tetapi untuk mobile learning mungkin didistribusikan lintas pelajar, panduan, guru, teknologi dan sumber daya di dunia seperti buku, bangunan, tumbuhan dan hewan.

- Konteks dikonstruksi oleh peserta didik melalui interaksi: Untuk mengeksplorasi kompleksitas mobile belajar itu perlu untuk memahami konteks di mana itu terjadi. Konteks harus dilihat bukan sebagai shell yang mengelilingi pelajar pada waktu dan lokasi tertentu, tetapi sebagai entitas yang dinamis, dibangun oleh interaksi antara peserta didik dan lingkungannya. Misalnya, pengunjung ke galeri seni terus membuat konteks untuk belajar dari jalur mereka melalui lukisan, tujuan dan minat mereka, dan sumber daya yang tersedia termasuk kurator dan pengunjung lainnya.

- Mobile learning dapat melengkapi dan bertentangan dengan pendidikan formal: Pembelajar dapat memperluas pembelajaran di kelas mereka untuk pekerjaan rumah, kunjungan lapangan, dan kunjungan museum dengan, misalnya, meninjau materi pengajaran pada perangkat seluler atau mengumpulkan dan menganalisis informasi menggunakan probe data genggam. Mereka juga dapat mengganggu lingkungan yang dikelola dengan hati - hatikelas dengan membawa ke dalamnya telepon multimedia 
mereka sendiri dan mesin permainan nirkabel, untuk mengadakan percakapan pribadi di dalam dan di luar sekolah (Sharples, 2002).

- Pembelajaran mobile menimbulkan masalah etika yang mendalam tentang privasi dan kepemilikan: Sistem seperti myLifeBits (Gemmell, Williams, Wood, Bell, \& Lueder, 2004) memberikan pengalaman wear yang dapat dikenakan penyelenggara 'yang memungkinkan orang untuk merekam kehidupan sehari-hari mereka sebagai suara dan gambar dan kemudian ingat mereka untuk refleksi nanti. Ini memiliki potensi untuk menjadi alat yang kuat untuk seumur hidup belajar dan membantu mereka yang mengalami ingatan yang gagal. Mereka juga dapat mengizinkan orang tua atau guru memantau setiap detail pembelajaran yang intim, sehingga bermain dan bersantai menjadi perpanjangan dari kegiatan sekolah, untuk diperiksa dan dinilai sebagai catatan prestasi yang berkelanjutan. Ini bisa dilihat sebagai visi yang sangat mengganggu masa kecil tanpa privasi, dan langkah pertama miliki sudah diambil ketika perusahaan membawa ke pasar perangkat penandaan elektronik untuk orang tua untuk melacak lokasi anak-anak mereka.

\subsection{Motivasi Belajar}

Menurut Clayton Alderfer (dalam Nashar, 2004: 42) Motivasi belajar adalah kecenderungan siswa dalam melakukan kegiatan belajar yang didorong oleh hasrat untuk mencapai prestasi atau hasil belajar sebaik mungkin. Motivasi dipandang sebagai dorongan mental yang menggerakkan dan mengarahkan perilaku manusia, termasuk perilaku belajar. Dalam motivasi terkandung adanya keinginan yang mengaktifkan, menggerakkan, menyalurkan dan mengarahkan sikap serta perilaku pada individu belajar (Koeswara, 1989 ; Siagia, 1989 ; Sehein, 1991 ; Biggs dan Tefler, 1987 dalam Dimyati dan Mudjiono, 2006) Untuk peningkatan motivasi belajar menurut Abin Syamsudin M (1996) yang dapat kita lakukan adalah mengidentifikasi beberapa indikatoryna dalam tahap-tahap tertentu. Indikator motivasi antara lain: 1) Durasi kegiatan, 2) Frekuensi kegiatan, 3) Presistensinya pada tujuan kegiatan, 4) Ketabahan, keuletan dan kemampuannya dalam menghadapi kegiatan dan kesulitan untuk mencapai tujuan, 5) Pengabdian dan pengorbanan untuk mencapai tujuan, 6) Tingkatan aspirasi yang hendak dicapai dengan kegiatan yang dilakukan, 7) Tingkat kualifikasi prestasi, 8) Arah sikapnya terhadap saasran kegiatan

\subsection{Implementasi Media Pembelajaran Berbasis M-learning Menggunakan Model Blended POE2WE Untuk Meningkatkan Motivasi Belajar Peserta Didik}

Untuk Meningkatkan Motivasi Belajar Peserta Didik Salah satu masalah dalam proses pengajaran di sekolah yaitu bagaimana cara aagar peserta didik mempunyai motivasi dalam belajar. Setiap peserta didik dilatih sesuai dengan kebiasan dan hobi yang dimiliki agar dapat meningkatkan motivasi. Motivasi yang dimilki peserta didik yaitu pekerjaan melakukan sesuat yang menarik dan mudah untuk dilakukan. Penerapan media pembelajaran berbasis mlearning menggunakan model yang sesuai dapat meningkatkan motivasi belajar peserta didik. Salah satu model yang sesuai sengan peningkatan otivasi belajar peserta didik yaitu model blended POE2WE.

Blended POE2WE merupakan inovasi pembelajaran blended learning dalam pembelajaran Fisika dengan model POE2WE yang dapat memberikan pengaruh yang positif bagi kegiatan belajar peserta didik. Menurut Lin (2017: 2-3) Adanya motivasi belajar pada peserta didik jika hal untuk melakukan pembelajaran bisa dilakukan dengan adanya kemudahan dan kesenangan, sehingga peserta dididk akan merasa termotivasi dengan hal tersebut. Menurut Wimmer (2016: 2-3) Beberapa peneliti menyakini bahwa kreativitas berupa 
masalah yang akan dipecahkan, sejumlah ide yang relevan, proses memberikan solusi dari divergen ke kn. Sebagaimana penjelasan sebelumnya bahwa masalah dapat dipecahkan dengan mengindentifikasi dan menyeleksi masalah sesuai dengan kreatif. Proses pembelajaran yang dilakukan peserta ddidik dengan dengan menggunakan model blended POE2WE akan dimudahkan dengan adanya media mobile learning. Mobile learning yang mudah untuk digunakan untuk siapa saja dan penyajian materi didalamnya yang menarik akan membuat suatu kemudahan bagi peserta didik dan rasa kertertarikan ke dalam pembelajaran akan meningkat. Adanya berbagai alasan yang membuat keyakinan dan pandangan guru sebagai pengajar dalam menerapkan model pembelajaran disesuaikan dengan kebutuhan dan tujuan yang dicapai. Di lain pihak, menurut Errington (2007: 41) penggunaan inovasi dalam pembelajaran yaitu dengan blog terkadang membutuhkan kekhususan pengajar agar dapat menyampaikan informasi secara interaktif.

\section{KESIMPULAN}

Berdasarkan hasil analisis dapat disimpulkan bahwa penerapan penggunaan model blended POE2WE berbasis m-learning dapat meningkatkan motivasi peserta didik dalam pembelajaran. Hal tersebut dapat dianalisis dari tingkat penggunaan smartphone yang meningkat dan kebiasaan peserta didik yang selalu menggunakan smartphone. Sehingga dalam menggunakan mobile learning peserta didik sudah terbiasa dan lebih memudahkan peserta didik dalam melakukan pembelajaran sekaligus mencari informasi tambahan dalam belajar.

Dengan adanya pengguanakan model blended POE2WE peserta didik dapat lebih aktif dan kreatif mengguanakan mobile learning dalam melakukan kegiatan pembelajaran face to face, dan dapat memotivasi peserta didik dalam pembelajaran mandiri karena adanya kemudahan dalam mengguanakan mobile learning. uk Meningkatkan Motivasi Belajar Peserta Didik.

\section{UCAPAN TERIMA KASIH}

Dengan selesainya penelitian ini, saya mengucapkan terima kasih kepada pihak yang telah berkontribusi dalam penelitian ini. Sehingga penelitian ini dapat terlaksana dengan baik. 


\section{DAFFTAR PUSTAKA}

Astuti, Irnin, A. D., Sumarni, Ria, A., \& Saraswati, Dandan, L. (2017). 57Pengembangan Media Pembelajaran Fisika Mobile Learning berbasis Android. Jurnal Penelitian \& Pengembangan Pendidikan Fisika, 3(1): 57.

Bersin, J. (2004). The blended learning book. San Fransisco: Pfeiffer.

Darling-Hammond, L., \& Bransford, J. (2005). Preparing teachers for a changing world: What teachers should learn and be able to do. San Francisco: JosseyBass .

Errington, E. (2004) The impact of teacher beliefs on flexible learning innovation: some practices and possibilities for academic developers. Innovations in Education and Teaching International, 41 (1): 39-47. Doi. 10.1080/1470329032000172702.

Fatimah, Siti. (2014). Pengembangan Media Pembelajaran IPA-Fisika Smartphone Berbasis Android Sebagai Penguat Karakter Sains Siswa. Jurnal Kaunia, 10(1): 59-64.

Gemmell, J., Williams, L., Wood, K., Bell, G., \& Lueder, R. (2004). Passive Capture and Ensuing Issues for a Personal Lifetime Store. In Proceedings of The First ACM Workshop on Continuous Archival and Retrieval of Personal Experiences (CARPE '04) (pp. 48-55). New York, NY, USA.

Lin, C. Y. (2017). Threshold effects of creative problem-solving attributes on creativity in the math abilities of taiwanese upper elementary students. [online]. Tersedia: https://doi.org/10.1155/2017/4571383. Diakses Pada Tanggal 16 Februari 2020.

Lubis, Isma, R., \& Ikhsan, Jaslin. (2015). Pengembangan media pembelajaran kimia berbasis android untuk meningkatkan motivasi belajar dan prestasi kognitif peserta didik SMA. Jurnal Inovasi Pendidikan Ipa, 1(2): 191-201.

Nana, Sajidan, Akhyar, M., \& Rochsatiningsih, D. (2014). The development of Predict, Observe, Explain, Elaborate, Write, and Evaluate (POE2WE) Learning Model in Physics Learning at Senior Secondary School. Journal of Education and Practice, 5(19): 56-65.

Nana. (2014). Pengembangan model POE2WE dalam pembelajaran Fisika SMA. Universitas Sebelas Maret.

Nana. (2016). Pengembangan Model Pembelajaran Prediction, Observation, Explanation, Elaboration, Write, and Evaluating (POE2WE) dalam Pembelajaran Fisika SMA. Universitas Sebelas Maret.

Nana. (2018). Penerapan Model Creative Problem Solving Berbasis Blog Sebagai Inovasi Pembelajaran Di Sekolah Menengah Atas Dalam Pembelajaran Fisika. Prosiding SNFA (Seminar Nasional Fisika dan Aplikasinya), E-ISSN: 2548-8325 / P-ISSN 2548-8317

Nashar. (2004). Peranan Motivasi dan Kemampuan Awal dalam Kegiatan Pembelajaran. Jakarta: Delia Press. 
Riyanto, Bambang, et al. (2006). Perancangan dan Implementasi Aplikasi Mobile Learning Berbasis Android. [online].

Tersedia: http://p4tkmatematika.org/file/ARTIKEL/Artikel\%20Teknologi/perancangan_imple mentasi_m learning.pdf. Diunduh tanggal 16 februuari 2020.

Sharples, M. (2002). Disruptive devices: mobile technology for conversational learning. International Journal of Continuing Engineering Education and Life Long Learning, 12(5/6): 504-520.

Sharples, mike., Taylor, josie., vavoula, Giasemi. (2005). Towards a Theory of Mobile Learning.

Thorne, K. (2003). Blended learning: How to integrate. London: Kogan.

Wimmer, L. (2016). Problem solving as a sufficient condition of the creative process: a case for closer cooperation of creativity research and problem solving research. Doi: 10.3389/fpsyg.2016.00488.

Yamin, M., \& Ansari, B. I. (2012). Taktik mengembangkan kemampuan individual siswa. Jakarta: Gaung Persada Press. 